\title{
Tumorigenicity assessment of cell therapy products: The need for global consensus and points to consider
}

\author{
Y. SATO ${ }^{1}$, H. BANDO ${ }^{2, \star}$, M. DI PIAZZA ${ }^{3}$, G. GOWING $^{4}$, C. HERBERTS $^{5, \dagger}$, S. JACKMAN $^{6}$, \\ G. LEONI ${ }^{7}$, S. LIBERTINI ${ }^{8}$, T. MACLACHLAN ${ }^{9}$, J.W. MCBLANE ${ }^{10}$, \\ L. PEREIRA MOURIÈS ${ }^{11}$, M. SHARPE ${ }^{7}$, W. SHINGLETON ${ }^{12, \dagger}$, B. SURMACZ-CORDLE ${ }^{7}$, \\ K. YAMAMOTO ${ }^{13} \&$ J.W. VAN DER LAAN ${ }^{5, \star}$
}

${ }^{1}$ Division of Cell-Based Therapeutic Products, National Institute of Health Sciences, Kawasaki, Japan, ${ }^{2}$ FUfIFILM Corporation, Tokyo, Fapan, ${ }^{3}$ Boehringer Ingelheim Pharmaceuticals, Ridgefield, Connecticut, USA, ${ }^{4}$ FUfIFILM Cellular Dynamics, Inc., Madison, Wisconsin, USA, ${ }^{5}$ Medicines Evaluation Board, Utrecht, The Netherlands, ${ }^{6}$ Charles River Laboratories, Horsham, Pennsylvania, USA, ${ }^{7}$ Cell and Gene Therapy Catapult, London, UK, ${ }^{8}$ Novartis Institutes for BioMedical Research, Basel, Switzerland, ${ }^{9}$ Novartis Institutes for BioMedical Research, Cambridge, Massachusetts, USA, ${ }^{10}$ Medicines $\mathcal{E}$ Healthcare Products Regulatory Agency, London, UK, ${ }^{11}$ Health and Environmental Sciences Institute (HESI), Washington, DC, USA, ${ }^{12}$ GE Healthcare, Cambridge, UK, and ${ }^{13}$ Takeda Pharmaceutical Company Limited, Tokyo, fapan

\begin{abstract}
Pluripotent stem cells offer the potential for an unlimited source for cell therapy products. However, there is concern regarding the tumorigenicity of these products in humans, mainly due to the possible unintended contamination of undifferentiated cells or transformed cells. Because of the complex nature of these new therapies and the lack of a globally accepted consensus on the strategy for tumorigenicity evaluation, a case-by-case approach is recommended for the risk assessment of each cell therapy product. In general, therapeutic products need to be qualified using available technologies, which ideally should be fully validated. In such circumstances, the developers of cell therapy products may have conducted various tumorigenicity tests and consulted with regulators in respective countries. Here, we critically review currently available in vivo and in vitro testing methods for tumorigenicity evaluation against expectations in international regulatory guidelines. We discuss the value of those approaches, in particular the limitations of in vivo methods, and comment on challenges and future directions. In addition, we note the need for an internationally harmonized procedure for tumorigenicity assessment of cell therapy products from both regulatory and technological perspectives.
\end{abstract}

Key Words: cell therapy, human pluripotent stem cells (hPSCs), international guidelines, in vitro testing, in vivo assay, tumorigenicity

\section{Introduction}

The field of cell-based regenerative medicine has been witnessing unprecedented growth in the past 10 years, as denoted by the increasing number of cell therapy products (CTPs) entering the clinical space to treat a wide range of severe conditions $[1,2]$.
Given the inherent complexity and heterogenous nature of CTPs, special considerations and requirements have emerged along their development path, often hindering the effective delivery of CTPs to patients as both regulatory hurdles and technical challenges. Notably, demonstrating that these products can be safely used in humans can pose some

Correspondence: Yoji Sato, PhD, Head, Division of Cell-Based Therapeutic Products, National Institute of Health Sciences, 3-25-26 East 4F Tonomachi, Kawasaki Ward, Kawasaki City, Kanagawa 210-9501, Japan. E-mail: yoji@nihs.go.jp

* Co-chairs of the HESI CT-TRACS Committee Tumorigenicity Working Group.

$\dagger$ Co-chairs of the HESI Cell Therapy-TRAcking, Circulation, \& Safety (CT-TRACS) Committee. 
unique challenges. Cells can elicit diverse functions and change their characteristics in response to the environment they are exposed to, which could lead to unpredictable and possibly undesired behaviors, such as immune reactions and unwanted toxicities. Thus, careful preclinical assessments and tailored strategies are absolute requirements to mitigate potential risks and facilitate clinical progression of novel CTPs. Among the key safety concerns, the risk of tumorigenicity has been a central debate in recent years as promising new CTPs derived from human pluripotent stem cells (hPSCs)-namely, human embryonic stem cells (hESCs) and human induced pluripotent stem cells (hiPSCs) - have been successfully developed for clinical use.

Since the world's first clinical trial of a CTP derived from hESCs to treat patients with spinal cord injury in the United States in 2010, several clinical trials of hESC-derived CTPs have been conducted in different countries, according to ClinicalTrials.gov. In addition, the world's first clinical research studies using autologous and allogeneic hiPSC-derived retinal pigment epithelial cells to treat patients with agerelated macular degeneration were initiated in Japan in 2014 and 2017, respectively. A clinical trial of allogeneic hiPSC-derived mesenchymal stromal cells (MSCs) for the treatment of steroid-resistant acute graft-versus-host disease began in the United Kingdom in 2017. In these clinical studies, understanding the potential of these products to form tumors in humans was of prime importance $[3,4]$.

In response to this emerging safety issue, the Health and Environmental Sciences Institute (HESI) launched a collaborative effort in late 2015 that ultimately established the HESI Cell TherapyTRAcking, Circulation, and Safety (CT-TRACS) committee, which is composed of more than 25 public and private sector organizations across the European Union, Japan and the United States, involved in cellular therapies development, their regulatory assessment and safety testing. HESI is a nonprofit institution whose mission is to collaboratively identify and help to resolve global health and environmental challenges through the engagement of scientists from academia, government, industry, non-governmental organizations and other strategic partners. The overarching mission of CT-TRACS is to facilitate the translation of cell-based therapies to the clinic by driving the development of tools, methods and scientific knowledge required to evaluate the safety and fate of therapeutic cells. In March 2016, the Forum for Innovative Regenerative Medicine (FIRM), the Japanese industry association for regenerative medicine, also established the Committee for Non-Clinical Safety Evaluation of Pluripotent Stem Cell-derived ProducT (FIRM-CoNCEPT) to provide regulatory science-based globally acceptable consensus for safety evaluation in the development of hPSC-derived products. A Japanese experimental public-private partnership initiative (Multisite Evaluation Study on Analytical Methods for Non-clinical Safety Assessment of Human-Derived Regenerative Medical Products [MEASURE]) was subsequently initiated with FIRM-CoNCEPT to validate six experimental methods for tumorigenicity and/or biodistribution. HESI CT-TRACS and FIRMCoNCEPT/MEASURE combined efforts to share the knowledge learned from these experimental studies and facilitate discussion with members of the scientific community, regulators and other stakeholders via joint workshops [5-10].

This position paper is the result of these joint discussions and describes the current challenges and new directions in tumorigenicity testing of CTPs, with a view to define an improved roadmap to support developers and regulators in key decision-making processes.

\section{Translating cell-based therapies to the clinic: assessing tumorigenicity risk}

Confirming the safety of CTPs is paramount for their effective clinical translation. Despite rapid advances in scientific knowledge of stem cell biology and the development of novel platforms for high-throughput cell screening, the extent of preclinical evidence required to mitigate the risk of potential unwanted side effects in patients is critically disputable. This is certainly a challenge in regard to assessing the tumorigenicity risk associated with a given CTP.

Tumorigenicity risk has been primarily linked to CTPs derived from hPSCs. Indeed, the undifferentiated cells present intrinsic tumorigenic properties and can form teratomas in immunodeficient animals, which have been ascribed to their pluripotency $[11,12]$. One of the main reasons for concerns about tumorigenicity is that if a few residual, undifferentiated hPSCs persist in the final CTP, these could initiate tumor development in transplanted patients (Figure 1). However, additional factors can contribute to the tumorigenic potential of a given CTP, such as accumulation of genomic aberrations during establishment of an hPSC line, cell transformation and mutations in proto-oncogenes or tumor suppressor genes, or genomic instability following prolonged cell passage [13]. Given the possible multifactorial etiology of tumorigenicity, defining a one-size-fits-all strategy to test such risk is not feasible. Rather, an indepth risk assessment based on the quality and safety attributes of a candidate CTP should be carried out to establish relevant safety testing methods and potential mitigation strategies, taking into account the intended patient population. 


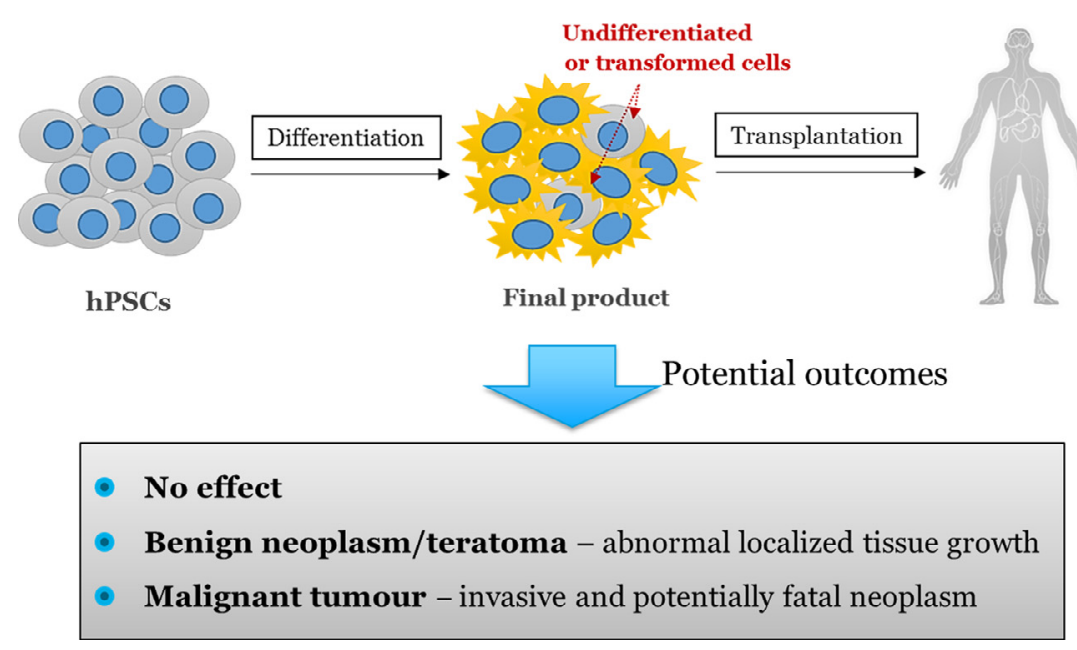

Figure 1. Rationale for tumorigenicity testing of PSC-derived products.

The conventional approach for tumorigenicity testing is based on the in vivo tumorigenicity assay, in which cells are implanted at an ectopic site (eg, subcutaneously, under the kidney capsule or testis capsule) in immunodeficient mice and monitored for the formation of tumor masses (as described in section 4.1). Although an in vivo tumorigenicity assay is often included in safety programs for CTPs, its sensitivity for CTPs can vary depending on the experimental conditions (eg, animal species and level of immunosuppression). This variation suggests that the in vivo tumorigenicity assay may not always be sensitive enough to detect a small number of hPSCs or transformed cells contaminating the final CTPs. Furthermore, when considering possible alternative methods, it is important to contemplate methods that align with the $3 \mathrm{Rs}$ principles (replacement, reduction and refinement of animals in research). Therefore, in vitro approaches need to be discussed in this respect.

Throughout its activities, CT-TRACS has identified the development of in vitro methodologies to assess tumorigenicity as a priority need for three main reasons: (i) concerns about the practical use of animals in testing CTP doses relatable to human application, (ii) concerns about the relevance of testing human cells in animals and (iii) interest in developing alternative methods contributing to the 3Rs (replacement, reduction and refinement) of animal use in research and development.

Section 4.2 introduces the various in vitro approaches that are available for the detection of residual hPSCs or transformed cells and can be applied in a quality control step during the product manufacturing process as well as for final products. Understanding of the value and limitations of these technologies is the basis for the case-by-case approach.

\section{The regulatory landscape}

Regulatory bodies worldwide, including the European Medicines Agency (EMA); US Food and Drug Administration (FDA); Japan Ministry of Health, Labour and Welfare (MHLW); and others, have introduced specific legislation and guidelines to support the development of cell therapy medicinal products intended for human use (Table 1). These guidelines provide a framework for the quality, safety and efficacy aspects that are considered for clinical trial approval and marketing authorization. Regulators also recognize that each CTP and the intended recipients may possess unique properties and risk profiles that will dictate the optimal strategy for their safety assessment. However, details on the type of assays to be conducted to address tumorigenicity risk are not yet provided as part of these guidelines.

With an increasing number of CTPs derived from hPSCs or other cell types harboring tumorigenic potential progressing toward the clinic, there is a need to improve current strategies for tumorigenicity assessment and ultimately harmonize them across different countries. Robust scientific evidence that can be used to drive future regulatory decisions will be pivotal to this process. Novel methodologies have been developed (see section 3) and proposed as complementary platforms to test the safety of hPSC-CTPs. Their potential incorporation into standard strategies for product quality and safety assurance will require robust validation through collaborative efforts. This is certainly a major challenge that must be taken forward for the successful translation of these products.

\section{EMA guidelines}

The EMA guideline on human cell-based medicinal products (EMEA/CHMP/410869/2006) 
Table 1. List of regulatory guidelines for cell-based therapies.

\begin{tabular}{|c|c|c|}
\hline Agency & Guideline & Reference \\
\hline \multirow[t]{4}{*}{ EMA } & Guideline on human cell-based medicinal products (EMEA/CHMP/410869/2006) & [14] \\
\hline & $\begin{array}{l}\text { Guideline on the nonclinical studies required before first clinical use of gene therapy medicinal } \\
\text { products (EMEA/CHMP/GTWP/125459/2006) }\end{array}$ & [76] \\
\hline & $\begin{array}{l}\text { Guideline on quality, nonclinical, and clinical aspects of medicinal products containing genetically } \\
\text { modified cells (EMA/CAT/GTWP/671639/2008) }\end{array}$ & [77] \\
\hline & Reflection paper on stem cell-based medicinal products (EMA/CAT/571134/2009) & {$[17]$} \\
\hline \multirow[t]{2}{*}{ FDA } & $\begin{array}{l}\text { FDA-CTGTAC Meeting \#45, Cellular Therapies Derived From Human Embryonic Stem Cells } \\
\text { (hESCs)- Considerations for Pre-Clinical Safety Testing and Patient Monitoring, April } 2008\end{array}$ & [19] \\
\hline & $\begin{array}{l}\text { Guidance for industry: Preclinical assessment of investigational cellular and gene therapy products } \\
\text { (FDA 2013) }\end{array}$ & {$[20]$} \\
\hline \multirow[t]{5}{*}{ MHLW } & $\begin{array}{l}\text { Guidelines on ensuring the quality and safety of pharmaceuticals and medical devices derived from } \\
\text { the processing of autologous human somatic stem cells (Notification No. 0907-2, PFSB/MHLW, } \\
7 \text { September 2012) }\end{array}$ & {$[21]$} \\
\hline & $\begin{array}{l}\text { Guidelines on ensuring the quality and safety of pharmaceuticals and medical devices derived from } \\
\text { the processing of allogeneic human somatic stem cells (Notification No. 0907-3, PFSB/MHLW, } \\
7 \text { September 2012) }\end{array}$ & {$[22]$} \\
\hline & $\begin{array}{l}\text { Guidelines on ensuring the quality and safety of pharmaceuticals and medical devices derived from } \\
\text { processing of autologous human induced pluripotent stem(-like) cells (Notification No. 0907-4, } \\
\text { PFSB/MHLW, } 7 \text { September 2012) }\end{array}$ & [23] \\
\hline & $\begin{array}{l}\text { Guidelines on ensuring the quality and safety of pharmaceuticals and medical devices derived from } \\
\text { processing of allogeneic human induced pluripotent stem(-like) cells (Notification No. 0907-5, } \\
\text { PFSB/MHLW, } 7 \text { September 2012) }\end{array}$ & [24] \\
\hline & $\begin{array}{l}\text { Guidelines on ensuring the quality and safety of pharmaceuticals and medical devices derived from } \\
\text { the processing of human embryonic stem cells (Notification No. 0907-6, PFSB/MHLW, } \\
7 \text { September 2012) }\end{array}$ & {$[25]$} \\
\hline WHO & $\begin{array}{l}\text { Recommendations for the evaluation of animal cell cultures as substrates for the manufacture of } \\
\text { biological medicinal products and for the characterization of cell banks (TRS 978, Annex 3). } \\
\text { [Note: These recommendations specifically exclude whole, viable animal cells such as stem cells } \\
\text { when they are used directly for therapy by transplantation into patients or when they are developed } \\
\text { into stem cell lines for the purpose of using them as therapeutic agents by transplantation.] }\end{array}$ & [26] \\
\hline
\end{tabular}

This list is restricted to documents on cell therapy products. Guidelines on gene therapy products are not included.

indicates in general terms that tumorigenicity should be studied "if the risk of cellular transformation can be foreseen" and testing should focus on proliferation capacity as well as on chromosomal integrity. This guideline also referred to the International Conference on Harmonization (ICH) Q5D guideline [15] and the European Pharmacopeia monograph on cell substrates [16]. The latter was considered state of the art at the time of writing of the guideline and provided guidance on the use of cells as substrates, not as therapeutics per se.

A 2011 EMA Committee for Advanced Therapies (CAT) reflection paper specifically focused on stem cell-based medicinal products (EMA/CAT/ 571134/2009) [17]. The committee recognized that there is an inherent risk of tumor formation in pluripotent as well as somatic stem cells, and culturing conditions can substantially influence the genomic instability of stem cells. Because undifferentiated and proliferative/pluripotent cells such as induced pluripotent stem cells (iPSCs) and hESCs have a relatively high risk of tumor formation, the committee stated that the presence of the latter cells should be limited and justified [17]. Furthermore, the committee indicated that prolonged cell culture might help to evaluate tumorigenicity and chromosomal stability. hiPSCs and hESCs are distinguished from somatic stem cells (eg, MSCs, hematopoietic stem cells [HSCs]), and teratoma formation is inherent to the pluripotent stem cells.

Following publication of the 2011 CAT paper, the EMA Cell Products Working Party held a workshop to discuss the issue of tumorigenicity in MSC-based therapies [18]. Participants discussed quality aspects of in vitro cell assays and acknowledged that MSCs are adult stromal cells with a limited possibility of expansion in culture. Barkholt et al [18] noted that MSCs differ from induced pluripotent stromal cells in this way. Because some cells may be more prone to develop chromosomal aberrations, participants also discussed whether these chromosomal aberrations may pose a risk to patients or could be self-contained (eg, by induction of apoptosis). Barkholt et al further described various analytical techniques to assess cytogenetic abnormalities but emphasized the lack of proper positive controls because transformed rather than immortalized cells should be used [18]. The nonclinical discussion focused on in vivo tests. The meeting experts indicated that there was no 
evidence of tumor formation after injection of human MSCs in immunocompromised mice. Current

in vivo models may not be predictive for tumor formation, as discussed in section 4 .

\section{FDA guidelines}

A 2008 FDA briefing document discussed the risks of hESCs in relation to teratoma formation [19]. According to the FDA, "assays used as process control and for lot release should include tests capable of detecting unacceptable levels of undifferentiated ESCs or other cellular impurities in hESC-derived cellular products that may form tumors, differentiate inappropriately or present other safety concerns" [19]. Methods such as flow cytometry and reversetranscription polymerase chain reaction (RT-PCR) analysis of gene expression were mentioned as possible solutions. However, the remainder of the document focused on preclinical considerations, which can be seen as animal experimentation. From this we infer that from the FDA guidelines perspective, the capacity for engraftment of cells can only be assessed with animal studies.

The FDA also further discussed the immunological tolerance of animals as a limitation to their use in detecting the tumorigenicity of CTPs [19]. The presence of adequate mouse $\mathrm{B}$ cells, $\mathrm{T}$ cells and natural killer cells was reported to interfere with tumor formation of implanted hESCs. Therefore, teratoma formation in Balb/c nude mice could indeed be induced by small numbers of mouse ESCs but was much less efficient with hESCs. The site of cell administration was also identified as important. The FDA discussed various examples of sensitivity to teratoma formation as well, showing that the site of cell implantation in the animal host strongly influenced the sensitivity in tumor detection [19].

In 2013, the FDA further issued a guidance for industry on preclinical assessment of investigational cellular and gene therapy products [20], in which the section on cellular therapy gave attention to the issue of tumorigenicity. The following factors were identified for consideration: the differentiation status profile, the extent of cell manipulation, the potential to induce tumor formation from existing host malignant cells and the target patient population. The FDA acknowledged that there was no scientific consensus regarding selection of the most relevant species or the ability of current animal models to predict outcome. Despite this difficulty, the guidance paper indicated that it is important that animal studies designed to show tumorigenicity show survival of the cells for a sufficient length of time. The paper further recommended delivering the product on the intended clinical anatomic site with a sufficient study duration.
MHLW guidelines

In 2015, Hayakawa et al published a series of guidelines on ensuring the quality and safety of pharmaceuticals and medical devices derived from processing human stem cells from different origin [21-25], which included English translations of the Japanese Notifications issued by the MHLW in 2012 (see Table 1). These guidelines follow a similar structure, including an explanation of general principles, manufacturing methods, stability, preclinical safety testing, potency testing, pharmacokinetics and analysis of clinical trials. Tumorigenicity is also discussed.

Chapter IV of the guideline on somatic stem cells (of both autologous and allogeneic origin) indicates that applicants should discuss the possibility of tumor formation (benign and/or malignant), taking into consideration the cell type and its characteristics $[21,22]$. If necessary, it is requested (or recommended) that studies be conducted on a suitable animal model. Specifications on criteria to assess the suitability of an animal model were not provided. The guideline emphasized that the final product should be tested. An intermediate product might be tested only when it is not possible to test a final product (eg, because of insufficient cell numbers).

The guidelines on autologous and allogeneic hiPSCs as well as on hESCs [23-25] differ from the previous guidelines in only one small sentence, but the nuance is important because they mention the need to investigate and discuss the possibility of tumor formation "using an appropriate animal model or other system." It is uncertain what "other system" means, but it could be an in vitro study.

\section{Open questions}

No guidance on follow-up has been given in the EMA and FDA guidelines published thus far. Some questions remain to be answered: What steps should be taken if the assay applied (either in vivo or in vitro) shows positive results (ie, evidence for tumorigenicity)? Should there be a limit on the manipulation of the cells? Furthermore, existing guidelines do not provide guidance on limits (eg, in terms of cell concentration limits), recommendations for further purification, and so forth. Barkholt et al [18] indicated that the risk for MSCs is minimal, and testing might be conducted with in vitro karyotyping. However, this leads to further questions: Should this test be conducted on a batch-release concept or only during development of the product? What about hiPSCs? Barkholt et al [18] indicate that there is an inherent risk of the induction of teratomas, which might be related to any of the following: the presence of undifferentiated cells, the extent of manipulation of the cells or the number of passages before reaching a population that is sufficient in number to be given to patients. 
The Japanese MHLW guidelines mention that "if there is a possibility of tumorigenicity or malignant transformation," the applicant should "provide justification considering the relationship with the anticipated efficacy" [21-25]. This is discussed in section 5 .

Although we currently do not have answers to these questions, they are relevant to the current work and are also discussed in section 5 .

\section{Strategy in tumorigenicity testing}

It is important to note that cell tumorigenicity is distinct from oncogenicity. The World Health Organization (WHO) defines oncogenicity as "the capacity of an acellular agent, such as a chemical, virus, viral nucleic acid, viral gene(s) or subcellular element(s), to cause normal cells of an animal to form tumors" [26]. This definition is synonymous with carcinogenicity as used in ICH Guideline S1 [27]. In contrast, tumorigenicity is associated with cells introduced into the body from the outside (even in the case of autologous cells). In other words, the tumors identified in an oncogenicity test are of host origin, whereas those identified in a tumorigenicity test are derived from inoculated cells. Theoretically, tumorigenicity testing for hPSC-derived CTPs applies to the detection of either residual undifferentiated cells or transformed cells in the final product (Table 2), both of which are considered "contaminants" or "impurities" to the final differentiated CTP.

\section{Detection of residual undifferentiated PSCs}

The tumorigenic potential of hESCs or hiPSCs is considered to be higher than somatic cells or somatic stem cells (eg, MSCs, which are also used as raw materials of CTPs) $[17,18,28]$. When hESCs or hiPSCs are used as materials to manufacture hPSCderived human cell therapy products (hCTPs) for therapeutic purposes, the quality of the hPSC starting material has a significant impact on the final biological product. To ensure quality control of hPSCs as the material of origin, it is essential to examine whether hPSC banks meet minimum criteria to consider them of "clinical grade" by implementing the appropriate quality control assays, such as karyotyping, pluripotency assessment and other standard assays associated with master cell banks [29].
Because undifferentiated hPSCs could possess tumorigenic potential, efforts to purify the final product and minimize its contamination with residual hPSCs are critical. Therefore, it is important to determine the limit of detection (LOD) of the assay methods to which undifferentiated cells can be observed (ie, the minimal number of cells able to induce a measurable tumor) as shown in relevant guidelines like ICH-Q2(R1) [30]. If the LOD is exceeded, then the applicant should take appropriate measures to remove these cells from the final product or fail the particular product lot $[3,31]$.

\section{Detection of tumorigenic transformed cells generated during product manufacturing}

During the cell manufacturing process, various treatments such as multiple passages during cell expansion may lead to the unintended transformation of individual cells, which carry the risk of becoming tumorigenic when implanted in a patient. From that point of view, tumorigenicity tests are helpful at the end of the manufacturing process to check for the presence of transformed cells.

Both of these hazards, the presence of residual undifferentiated cells or of transformed cells in the final product, can be detected by in vivo and in vitro methods, described in sections 4 and 5 , respectively.

\section{State of the art for in vivo and in vitro tumorigenicity testing}

\section{In vivo tumorigenicity testing}

Animal studies constitute one of the pillars of preclinical safety assessment in the development of traditional drugs. The translation of the results to humans is often debated and even more so in the case of CTPs testing because it implies that human cells would behave the same in an animal model as in the human body. That being said, currently there is no better alternative available, and regulatory guidelines are requiring in vivo tumorigenicity assays on certain instances, as reviewed in section 2 .

For in vivo assessment, several factors need to be considered before embarking on a new product regulatory submission enabling tumorigenicity study. These factors include selection of the animal model,

Table 2. Key risk factors contributing to tumorigenicity risk.

\begin{tabular}{ll}
\hline Hazards & Risk factors \\
\hline Residual PSCs in a CTP & Contamination of final product with residual PSCs \\
$\begin{array}{l}\text { Transformation of cells } \\
\text { in a CTP }\end{array}$ & Cell transformation and activation of tumorigenic networks, such as during cell expansion, cell transduction \\
Genetic instability & with integrating vectors, differentiation/activation process of cells for the manufacture of CTPs \\
\hline
\end{tabular}


the number of cells to be inoculated, the study duration, the need for controls, the LOD and the site of transplantation, among others. The following subsections provide considerations and current practices gathered from therapy developers, regulatory scientists and other professionals with hands-on experience developing study designs for in vivo tumorigenicity safety assessment, when one is recommended.

\section{Animal models}

A significant number of immunocompromised animal models are commercially available, including severely combined immunodeficient (SCID) mice, which have been suggested as a reasonable platform for in vivo tumorigenicity assessment. For example, NOD/SCID/ $\gamma$ Cnull (NOG) mice [32] and NOD/SCID/IL-2r $\gamma \mathrm{KO}$ (NSG) mice [33], both of which are defective in T-cell, B-cell and natural killer-cell function, have been shown to exhibit higher rates of human cell/tissue engraftment compared with conventional T-cell-defective nude mice recommended in the WHO 61st report from the Expert Committee on Biological Standardization [26] and by others [4,34-36]. In other work, engraftment of human cells has been successfully shown in immunodeficient rats in both short- and long-term studies [37-40]. Although some models have incomplete immunodeficiency (eg, the athymic nude rat), they may be preferred for various reasons, including a large size that enables higher dosage with the cell product and facilitates complex surgical administration (intraspinal, intramyocardial, etc) than the smaller mouse models.

Selection of the animal model may revolve around multiple parameters, and the advantages and disadvantages of each model should be taken into consideration during the experimental design. Regardless of the model selected, proof of engraftment and survival of the transplanted cell product must be successfully demonstrated to design a valid tumorigenicity study. However, animal models remain inherently flawed because they often do not replicate the human paradigm, including the many subtleties associated with a diseased state. Moreover, the engrafted cells remain a xenograft surviving in the host due to immunodeficient background. Overall, the currently available models are limited and may not be appropriate for the proper assessment of tumorigenicity potential associated with CTPs. At this time, there is no global consensus about the number of animals and the controls required to show that a tumorigenic event is unlikely to occur.

Impact of tumor microenvironment, transplantation sites and dosage for in vivo tumorigenicity testing

The FDA has given attention to the tumor microenvironment as an important point to consider in the assessment of tumorigenicity testing for CTPs [19]. As such, in current practice, hCTPs are typically inoculated into animal models at the clinical equivalent transplantation sites and, to the extent possible, via the clinical route intended for patients. However, the rationale for this type of approach is not discussed in detail by the FDA [19] and is still debated.

Several papers discuss the impact of the microenvironment in tumorigenesis [41-43]. Wang et al recently summarized these aspects for human cancer [44]. The list of players in the human microenvironment is extensive, including platelet-derived growth factor, tumor necrosis factor- $\alpha$, interleukin- 12 and fibroblast growth factor-2, to name only a few. These factors individually show high human specificity (ie, they are specific for stimulating human receptors), which indicates that the tumor microenvironment can hardly be modeled in a mouse. Even a humanized transgenic mouse (bearing many human receptors) would insufficiently mirror the human microenvironment, although it is currently recommended that hCTPs be inoculated into animal models [19] (see section 4.1). Emulating the patient paradigm is critical to properly assess the probability of tumor formation from an hCTP. Unfortunately, although many diseases are successfully modeled in rodents, cell transplantations in these animals will rarely fully replicate the disease state at the time of transplantation in patients. Moreover, animals have a reduced life span compared with humans, thereby limiting their use for longitudinal tumorigenicity assessments.

In the regulatory guidelines discussed earlier, in vivo tests are taken as valuable for the assessment of cell behavior at the engraftment site. These guidelines indicate that hCTPs should be administered at the same dose that actual patients will receive or the maximum feasible dose. In cases in which physical hindrances make it difficult to transplant the same number of cells into the small animal model, the number of cells can be scaled down to the maximum feasible dose. Alternatively, when a CTP is injected directly into a specific region of interest (eg, a select area of the brain, spinal cord, heart or eye), one may consider scaling the dose based on organ weight or volume of the target treatment area, thereby keeping the ratio of transplanted cell to engraftment area, in addition to other biological variables such as gender of target patients, analogous to the human paradigm.

\section{In vitro assessment, the next frontier in tumorigenicity testing}

Several in vitro assays are available to determine the number of residual undifferentiated hPSCs (eg, flow cytometry and quantitative RT-PCR) as described in Table $3[45,46]$. These assays are highly sensitive and robust, thus allowing for an accurate estimate of the number of residual hPSCs not only in the final product but also in intermediate products (ie, in intermediate phases of the product development). 
Table 3. List of in vitro tumorigenicity-associated tests and their respective advantages and disadvantages.

\begin{tabular}{|c|c|c|c|c|}
\hline Purpose & Methodology & Measurement items & Advantage & Disadvantage \\
\hline $\begin{array}{l}\text { Detection of pluripotent } \\
\text { stem cells }\end{array}$ & Flow cytometry [45] & $\begin{array}{l}\text { Protein markers for pluripotent } \\
\text { stem cells }\end{array}$ & $\begin{array}{l}\text { - This assay is rapid ( } \sim 1 \text { day) } \\
\text { - It is occasionally more sensitive } \\
\text { than the conventional soft agar } \\
\text { colony formation assay }\end{array}$ & $\begin{array}{l}\text { - This assay detects only cells expressing } \\
\text { known protein markers } \\
\text { - Gating techniques strongly influence } \\
\text { the results }\end{array}$ \\
\hline
\end{tabular}

Detection of immortalized cells

Detection of anchorageindependent

cell growth (colony

forming capacity

in semisolid media)

Detection of genomic instability $[5,13,82]$

\section{Karyotype analysis}

FISH assay

Genome sequencing by NGS serial passage) $[47,48,81]$

Digital soft agar colony

formation assay [49]
Gene markers for pluripotent digital PCR $[45,46]$

Highly efficient culture of

pluripotent stem cells [78]

Detection of marker molecules released into culture medium $[79,80]$

Cell proliferation assay (after

Colony formation of malignan transformed cells

$$
\text { stem cells }
$$

Colony formation

of pluripotent stem cells

Marker molecules for

pluripotent stem cells

Cell proliferation rate

ony formation assay

- It can distinguish, separate and collect individual cells

- This assay is simple and rapid

(approximately $6 \mathrm{~h}$ )

- This assay is simple and as

sensitive as quantitative RT-

PCR and droplet digital PCR

- These assays are simple and

enable noninvasive monitoring

of pluripotent stem cells

- This assay is simple and inexpensive

- It is more sensitive than using nude mice for detecting immortalized and nontumorigenic cells

- This assay is rapid (a few weeks

to 1 month)

- It is highly sensitive, compared with conventional soft agar colony formation assay, detecting one HeLa cell in $10^{7}$ human mesenchymal stromal cells

Number, size, and structure of chromosomes

Genomic copy number

variations

Localization and quantitation of specific DNA sequences

on chromosomes

Genomic single nucleotide

variants and copy number variations

- These assays have been technically established at least for genotoxicity assessment of chemicals

- NGS enables extensive analysis of genomic abnormalities

- This assay detects only cells expressing known gene markers

- It takes time to detect trace amounts of pluripotent stem cells

- Results are influenced by components of the culture medium and other cell culture conditions

- It takes time to detect trace amounts of contaminating immortalized cells

- This assay cannot be applied to floating cells excluded from anoikis

- A high content imaging system is

necessary

- It cannot detect hPSCs because of dissociation-induced apoptosis

- Correlation between genetic aberration and tumorigenicity is obscure

- These assays cannot detect trace amounts of tumorigenic cellular impurities in hCTPs 


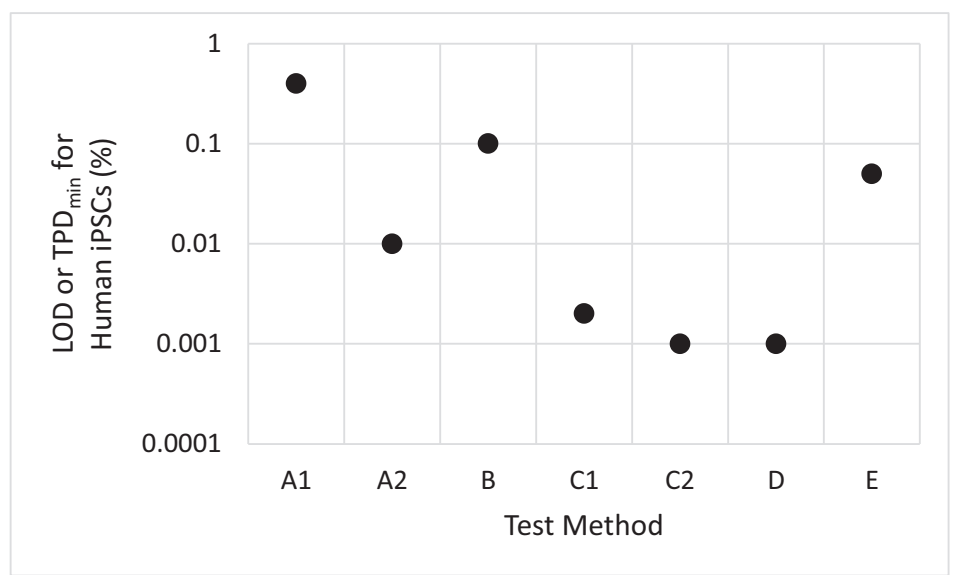

Figure 2. Representation of various limits of detection (LODs) or minimal tumor producing doses $\left(\mathrm{TPD}_{\min }\right)$ for hiPSCs in normal cells, retrieved from the literature. (A1) $\mathrm{TPD}_{\min }$ of in vivo tumorigenicity test using NOG mice [4] (hiPSCs in human retinal pigment epithelium cells [subcutaneous injection]). (A2) TPD ${ }_{\min }$ of in vivo tumorigenicity test using NOG mice [12] (hiPSCs in human neonatal dermal fibroblasts [subcutaneous injection]). (B) LOD of flow cytometry [45]; (hiPSCs in human retinal pigment epithelium cells). (C1) LOD of conventional RT-PCR [45]; (hiPSCs in human retinal pigment epithelium cells). (C2) LOD of droplet digital PCR [46]; (hiPSCs in human cardiomyocytes). (D) LOD of highly efficient culture method [78]; (hiPSCs in human mesenchymal stromal cells). (E) LOD of GlycoStem-HP method [79] (hiPSCs in HEK293 cells).

To detect the presence of unintended transformed cells, the cell proliferation assay $[47,48]$ and the digital soft agar colony formation assay [49] may be used. Both assays have been demonstrated to effectively detect even miniscule amounts of transformed cells from the intermediate products. The conventional soft agar colony formation assay has long been used to monitor anchorage-independent cell growth and to detect malignant cell transformation; however, recent studies showed that conventional method is not sensitive enough to detect transformed cells in hCTPs, contrary to the digital soft agar colony formation assay $[36,49]$.

The establishment of best practices and validation of new methods that could be implemented into a tumorigenicity risk assessment plan is a good starting point. However, it should not be applied as an exhaustive "checklist" because each product, as well as the targeted patients, has different characteristics and unique properties (as described in section 2).

\section{Utility of in vitro tests}

As shown in Table 3, in vitro tests associated with tumorigenicity were developed recently. It is of note that in terms of detection of residual undifferentiated hPSCs or transformed cells in hCTPs, some in vitro methods, such as RT-PCR-based and highly efficient culture methods for detection of residual hPSCs and digital soft agar colony formation assays for detection of transformed cells, may be more sensitive than currently available in vivo methods based on the use of severely immunodeficient animals (Figures 2 and 3). The risk of tumor formation from hCTPs is

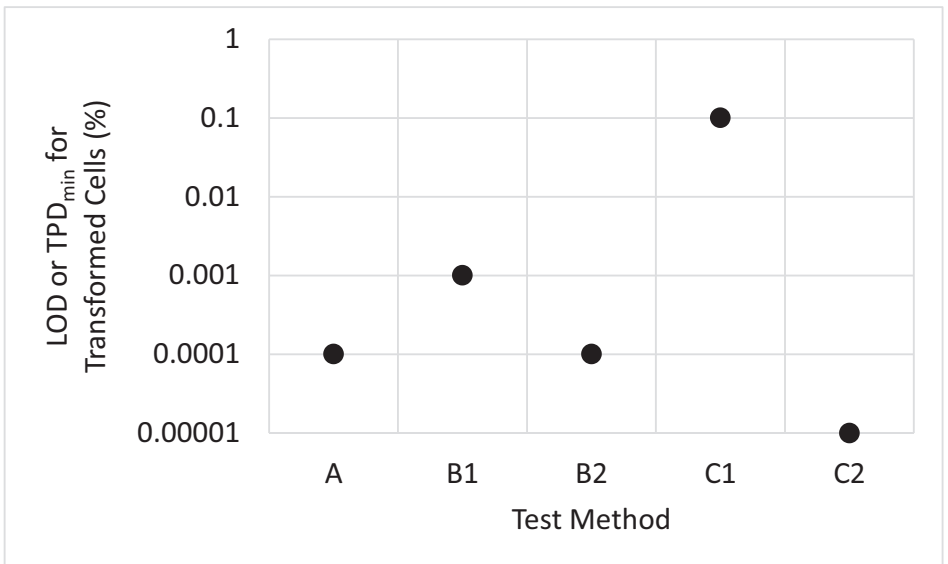

Figure 3. Representation of various limits of detection (LODs) or minimal tumor producing dose $\left(\mathrm{TPD}_{\min }\right)$ for transformed cells in normal cells, retrieved from the literature. (A) $\mathrm{TPD}_{\min }$ of in vivo tumorigenicity test using NOG mice [36] (HeLa cells in human MSC [subcutaneous injection]). (B1) LOD of cell proliferation assay after serial passage [48] (immortalized human MSCs in human MSCs). (B2) LOD of cell proliferation assay after serial passage [48] (HeLa cells in human MSCs). (C1) LOD of conventional soft agar colony formation assay [36] (HeLa cells in human MSCs). (C2) LOD of digital soft agar colony formation assay [49] (HeLa cells in human MSCs). 
determined by the probability of the harm caused by a tumor formation and its consequences. This probability is determined by the amount of hazards present (eg, residual hPSCs and transformed cells) and the impact/unit hazard. As mentioned in previous sections, the clinical impact/unit hazard can be difficult to estimate in nonclinical animal studies of hCTPs, owing to species differences and immune rejection between animals and humans as well as the unavailability of an uncertainty factor for cell dosage. In addition, the probability of tumor formation in clinical settings is rarely speculated because hCTPs are usually used for advanced therapies, for which there is little clinical experience available at present. Therefore, the basic strategy for the mitigation of tumorigenicity risk is to reduce the number of impurities (ie, residual hPSCs and transformed cells) in the hCTPs. In this context, sensitive in vitro tests may be useful tools for quality control of the hazards associated with tumorigenicity, which could help minimize in vivo tumorigenicity tests using animal models.

\section{Understanding the impact of genetic instability}

Genetic instability is a potential hazard that can affect the tumorigenicity of hCTPs. It is manifested as an accumulation of genetic mutations, gene amplification, karyotypic abnormalities or chromosomal rearrangement, any of which could increase the risk of cellular transformation in the final products $[50,51]$. Although the factors influencing genetic stability may differ depending on the cell type and/or culture methods $[29,52-54]$, it is advisable to minimize the duration of cell culture and the number of passages as much as possible and to assess the genetic stability of hCTPs before therapeutic use [29].

Assays used to determine the genetic stability of hCTPs include G-banded karyotyping, fluorescence in situ hybridization (FISH), array comparative genomic hybridization (aCGH), single nucleotide polymorphism (SNP) array and next-generation sequencing (NGS) (Table 3). G-banded karyotyping allows for detection of aneuploidy, chromosomal translocation and other karyotypic abnormalities. This method is useful to determine whether cultured cells still maintain a normal diploid karyotype after a certain number of passages or cell divisions, thus providing a rough indicator of genetic stability. On the other hand, aCGH is suitable for detection of DNA copy number variations in a relatively smaller genomic region. FISH and NGS may also be employed to analyze genetic instability; however, the experimental protocols and the interpretation of data resulting from either method for this purpose have not been fully established.

There are, however, key questions that remain to be elucidated, such as how to scientifically interpret the data from assays informing about the presence and number of genetic modifications and how to establish the correlation between the data and the actual risk for tumor formation of these cells. In fact, the presence of a mutation may not always be translated into an observed phenotype $[55,56]$. Furthermore, the level of sensitivity to detect genetic mutations (mutation type and frequency) and the choice of appropriate controls are critical factors that can affect the type of results obtained for a same product. Once these questions are clarified, digital karyotyping [57] may eventually replace G-banded karyotyping, which is time-consuming and less suitable for detection of genetic mutations.

In the future, genetic stability testing may be helpful in characterizing the quality and safety of hCTPs. At present, however, such assessment is not mandatory and has been performed to obtain reference information.

Emerging technologies in preclinical tumorigenicity assessment The possibility of culturing human tissues in vitro on microfluidic chips (organs-on-chips technology), ultimately with patient-derived cells and with the incorporation of immune cells, could generate a more representative, human-like microenvironment [58]. Although they are in early phase of development, human organ-on-chip models of cancer metastasis could become a useful alternative because both the transplantation organ and organs that are most likely to be affected by tumor colonization could be analyzed. Extensive studies and improvement of the current technologies are required to reach this stage, but several proof-of-concept studies have highlighted the potential of this approach (reviewed by Caballero et al [59]).

\section{Points to consider before clinical applications}

To determine the risk-benefit profile before using CTPs in patients, it is important to consider potential mitigation strategies to put in place in the event factors contributing to the risk of tumor formation are inevitable and the benefits of the therapy outweigh the risks.

\section{Management of risk related to CTP properties}

As discussed earlier, examples of hazards that may affect the risk of tumor formation after CTP administration are the presence of residual hPSCs and the occurrence of cell transformation events during the product development (Table 2). If the cells inducing tumor formation and/or hyperplasia can be identified and eliminated, the CTP may be still considered suitable for clinical use as long as corrective measures are adopted before proceeding further. For example, during the 2008 preclinical study of AST-OPC1 (an oligodendrocyte progenitor-based CTP for spinal cord 
injury), Geron Corporation detected a relatively high number of human-derived epithelial-like cysts [60]. The clinical trial was put on hold as a result of these findings. Geron was required to evaluate whether the formation of cysts was due to the AST-OPC1 product itself or to the presence of contaminants; in the case of contaminants, the company was also required to identify markers that could be used to exclude those impurities. In doing so, Geron could (i) prove that the contamination of AST-OPC1 with residual human epithelial progenitors was responsible for the ectopic cyst formation and (ii) quantify the minimum number of contaminant cells associated with this phenotype. Once Geron was able to provide clinical lots containing minimal levels of contaminant cells, the trial was allowed to restart in 2010.

As in the preceding example, HESI CT-TRACS is of the opinion that these risks should be mitigated via the use of thorough quality control assays on the final product. Last but not least, all stakeholdersregulators, academics and developers-are learning from each other as more of these therapies reach the patients. It is important that more examples like that of Geron are shared. Indeed, sharing strategies, successes and failures will help gather the knowledge necessary to define a harmonized innovative road map to support the safe and effective development of new revolutionizing CTPs.

\section{Management of risk associated with patient background}

Other risk factors independent of the product itself, such as the use of immunosuppressive drug regimens and patient history, may also influence tumor formation. For example, immunosuppression, which is intended to facilitate engraftment and therefore the primary therapeutic effect of the administered cells, can also contribute to reduce the surveillance functions of the immune system and may increase the risk of CTP-dependent or CTP-independent tumor formation. In this case, discontinuation of the immunosuppressants may be an option to manage a risk related to induction of immune rejection $[61,62]$. Ideally, datadriven recommendations should guide the duration and use of immunosuppression (eg, use only for a limited period time after product administration).

It is also important to consider individual propensity for tumor formation because this risk may be variable across specific patient populations (eg, those with specific cancer history or with different immunological status). Patients receiving a CTP to treat advanced cancer are at greater risk of tumor formation than a comparator population without cancer [63-65]. This risk is not only attributable to the risk of cancer recurrence when the effect of the cell therapy may have waned or because of CTP treatment failure, but it is also due to the risks associated with the use of cytotoxic chemotherapy or radiotherapy.

\section{Regulatory guidelines and management of risk}

At the time when the initial data are presented to regulatory authorities for review or approval of a novel CTP, the number of patients treated and the duration of their follow-up post-treatment are likely to be limited. Both of these factors reduce the chance that an unacceptable risk of tumor formation is identified before a decision is made on whether to license the product. However, in an application for a new drug, it is not expected that there is sufficient clinical experience to give definitive information on tumorigenicity risk. Consideration of the limitations of the data set needs to be presented in the marketing authorization application.

In addition to the guidelines mentioned in Table 1 regarding the preparation and nonclinical testing of CTPs, the EMA also released a reflection paper on stem cell-based medicinal products (EMA/CAT/571134/ 2009) [17]. This paper recommended genetic analysis in the case of observed tumor formation to investigate whether this is due to the administered product or just the result of endogenous tumor formation. In November 2017, the EMA released a draft revision [66] of the guideline on safety and efficacy follow-up and risk management of advanced therapy medicinal products (EMA/CHMP/149995/2008) for consultation. This revision takes into consideration the experience gained with the authorization of these medicines and with scientific advice and protocol assistance. The guideline also provides advice on (i) the early detection of risks during development, including a framework for the effective mitigation of their consequences for patients; and (ii) the design of appropriate post-authorization studies to follow up on the safety and efficacy of these medicines. The latter guideline indicates the expectations at the time of application and, importantly, includes methodologies to identify subsequent tumor development in patients by, for instance, passive or active surveillance, observational studies or patient registries or methodologies used to distinguish the origin of tumor in a patient by genetic analyses. Long-term follow-up using an extensive patient registry would be important to confirm the long-term safety profile [67-70].

\section{Defining future directions}

The importance of gathering and sharing data as much as possible has been emphasized multiple times and identified as a need for the successful development of safe and effective cell-based therapies [71,72]. In this section, we describe recent efforts initiated in Japan, a country that has shown leadership in the development 
of cell therapies, and the pursuit of these efforts at the international level with an initiative being launched by HESI CT-TRACS to generate science-based evidence needed to reach a globally acceptable consensus on methodologies for tumorigenicity evaluation, which is critically important not only for product developers but also for regulatory authorities and patients.

\section{FIRM-CoNCEPT/MEASURE preliminary studies: data sharing and international discussion}

The FIRM-CoNCEPT/MEASURE public-private partnership initiative conducted a multi-site experimental study funded by Japan's Agency for Medical Research and Development (AMED; the equivalent of the National Institutes of Health in Japan), aiming to evaluate various in vitro methodologies for the detection of residual undifferentiated cells or transformed cells. This study is in its reporting stage and is expected to be published soon. Preliminary results were shared in 2018 with international stakeholders to generate input and stimulate the field to move forward in a transparent and coordinated manner $[5,10,73]$.

\section{Methodologies and parameter choices}

The test methods used by FIRM-CoNCEPT/MEASURE revealed that several choices are to be made when conducting these assays, and global consensus on these approaches is needed.

- Detection of residual undifferentiated pluripotent stem cells. The selected methodologies were the highly efficient culture (HEC) assay and the droplet digital PCR assay.

- HEC assay: MSCs were used as the basis of this assay and to find the optimal conditions enabling the growth of undifferentiated iPSCs in the HEC. For the preliminary study, FIRM selected three clones and two culture conditions. Alkaline phosphatase (ALP) was used as the cell marker to identify iPS cell clones. However, ALP cannot be used for products expressing ALP (eg, chondrocytes). For these cases, another cell marker should be selected. Agreement is needed on the choice of MSCs as the basis of this assay.

- RT-PCR. FIRM has selected LIN28 as a pluripotent marker gene of iPSCs for the evaluation of this assay type. Discussions are ongoing to identify other possible markers. Agreement is needed on the choice of this approach.

- Detection of transformed cells. For this purpose, the digital soft agar colony formation assay and the cellular immortality testing assay were selected as the methods of choice.

- Digital soft agar assay. This assay is planned for use with MSCs as the basis, and a choice was made to use HeLa cells as the positive control. $\mathrm{HeLa}$ cells were chosen as positive controls because of their known high proliferative nature (tumorigenic potential) and because they are widely accessible and well characterized. Discussions are ongoing to identify other positive controls that are more reflective of the growth of transformed cells.

- Cellular immortality testing. This assay was designed based on the use of MSCs, with HeLa cells used as the positive control. HeLa cells are introduced in the assay after passage 4 in different numbers, followed by four to six additional passages. Each passage increases the sensitivity of the assay but also increases the time to completion (ie, more resources and time to be taken into account when planning for it).

- Defining the predictive power of the selected in vitro assays. The outcome of these in vitro assays (defined as sensitivity to the positive control) will be compared with an in vivo study for tumorigenicity evaluation of residual undifferentiated pluripotent stem cells. FIRM/MEASURE has conducted an in vivo study component in their program. Their upcoming final report will be valuable in understanding how sensitive and how predictive the selected methods are.

The main objectives and deliverables for the MEASURE multisite studies were

- to develop standardized protocols that can be used as a reference,

- to confirm the sensitivity of each assay to detect relevant contaminant cells,

- to identify technical difficulties that cause variation of the results, and

- to understand the nature of inter- and intra-facility differences.

\section{HESI CT-TRACS future plans}

On the basis of these preliminary reports, knowledge exchange and ongoing discussions with MEASURE studies participants, it is proposed that an international multisite study be formed to further evaluate the in vitro methods for tumorigenicity assessment, within HESI CT-TRACS, involving the participation of globally acting partners from the European Union, United States and other areas (Figure 4). It is important to reach agreement to establish the final protocols for such an evaluation to obtain greater global acceptance of the in vitro approaches. With that perspective, discussions are ongoing to refine the protocols and assay parameters, as well as to 


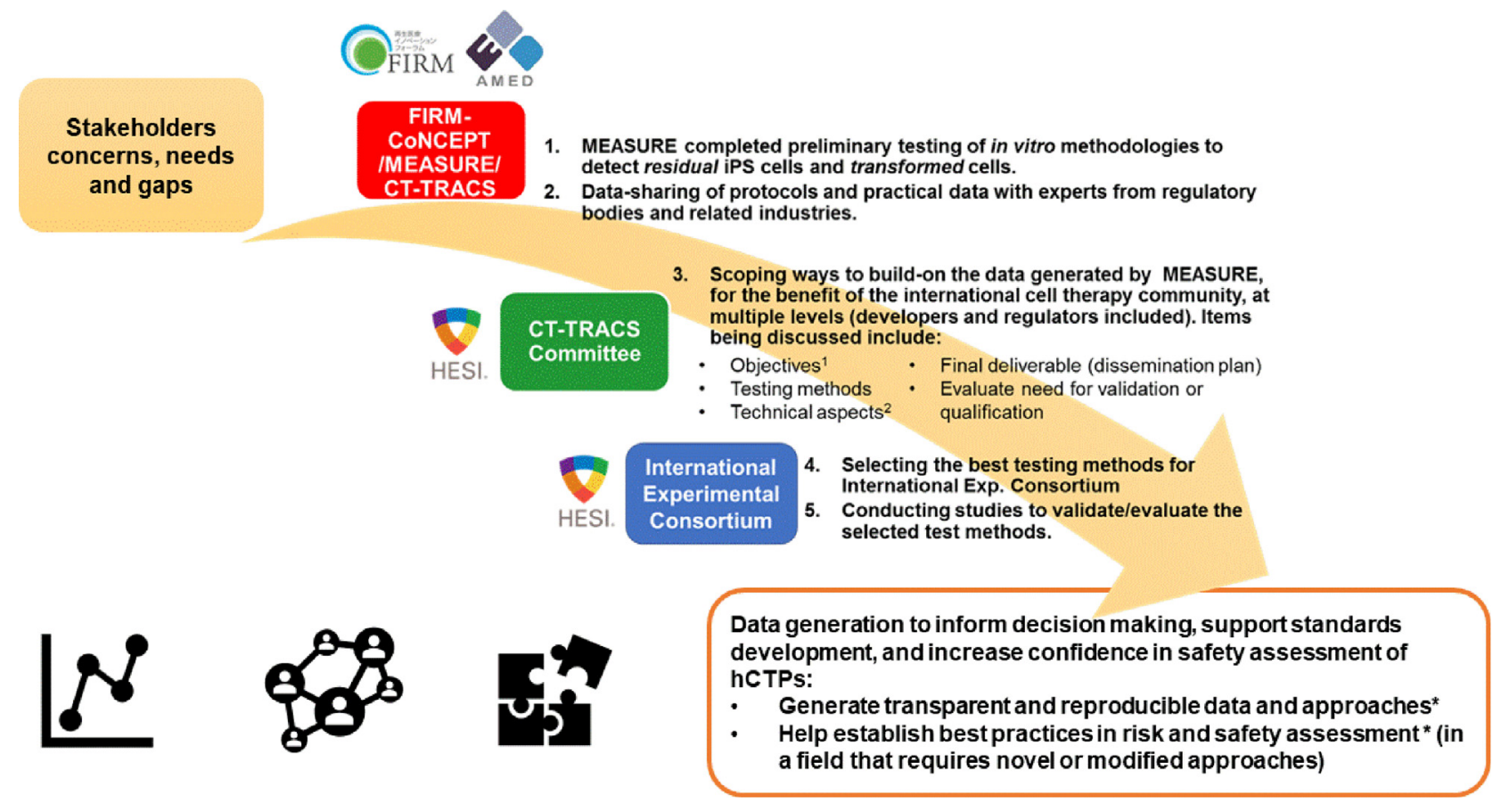

Figure 4. Tumorigenicity Testing of CTPs: CT-TRACS contributions and future directions. (i) Objectives include addressing concerns about the practical use of animals in testing doses relatable to human application; addressing concerns about the relevance of testing human cells in animals; compliance with need to develop alternative methods contributing to the 3Rs of animal use in research and development. (ii) Technical aspects being discussed include reference cells, positive control and markers. ${ }^{\star}$ Core aspects of HESI's mission and objectives.

confirm with regulators that these methodologies represent useful tools to generate relevant data necessary to inform decision-making. To our knowledge, there is no similar initiative at the international level at this time. A multi-site international initiative would increase the technical capability of researchers, increase the quality of assays and allow developers/regulators around the world to understand the tumorigenic potential of the cell therapy products based on the results from established assays which could be applied consistently https://hesiglobal.org/ cell-therapy-tracking-circulation-safety-ct-tracs/. To launch the initiative, HESI opened and disseminated a public call for participants from June 30, 2019 to August 30, 2019 (https:/hesiglobal.org/wpcontent/uploads/ sites/11/2019/07/Call-for-participants_HESI-Tumorige nicity.pdf) and held an in-person kickoff meeting on September 27, 2019 in Washington DC, with organizations from the public and private sector who responded to the call. New interested parties are encouraged to contact the authors for more information.

\section{Conclusions}

There are reports in the literature of patients who have developed tumors after some form of cell therapy, whether allogeneic [74] or autologous [75]. These isolated case reports are not related to licensed medicinal CTPs, but they highlight the possibility that such events may occur, and the risk needs to be considered during CTPs development.

Because undifferentiated hPSCs are intrinsically tumorigenic, developers of hPSC-derived products have to date established customized assays and tested their products on a case-by-case basis. Although such a caseby-case approach is reasonable, it is desirable to have a suite of qualified assays for which the ability to detect undifferentiated cells or transformed cells is well characterized so these can be applied to any relevant therapy in development, bringing consistency in the approach.

No detailed guideline document for tumorigenicity assessment of hCTPs, including hPSC-derived products, has been issued thus far. The basic strategy for the reduction of the tumorigenicity risk is the minimization of residual hPSCs and transformed cells in hCTPs, for which highly sensitive in vitro tests for detection of the tumorigenic cellular impurities may be viable options, although standardization and qualification of these test methods need to be achieved.

In Japan, a multisite validation study on the in vitro test methods has been conducted as a public-private partnership initiative called MEASURE. These studies were conducted to set initial protocols as references, confirm the sensitivity of each assay to detect tumorigenic cells, and understand intra- and interfacility variability. HESI CT-TRACS is playing a key role as an international, multi-sector collaborative platform for discussing the outcomes of this study, the 
performance of various test methods to assess the tumorigenic potential of hCTPs and to reach consensus among stakeholders on acceptable characteristics of hCTPs. We hope that our planned activities will provide a basis to inform international guidelines and provide science-based evidence to enhance confidence in the safety of regenerative medicine and cell therapy.

\section{Declaration of Competing Interest}

This work was supported by the Health and Environmental Sciences Institute (HESI) Cell TherapyTRAcking, Circulation, and Safety (CT-TRACS) Committee and by Japan's Agency for Medical Research and Development (AMED) under grant nos. JP19mk0104080j0003 and JP19mk0104101j0003.

HESI is a non-profit scientific organization that facilitates public and private partnerships in human and environmental health.

H. Bando, M. Di Piazza, G. Gowing, S. Jackman, S. Libertini, T. MacLachlan, W. Shingleton and K. Yamamoto are employees of companies developing cellular therapies, providing testing, or enabling technologies for the manufacturing of cellular therapies. The other authors have no commercial, proprietary or financial interest in the products or companies described in this article.

\section{Author Contributions}

Conception and design of the manuscript: YS, HB, SJ, GL, TM, JWM, LPM, WS, KY and JWvdL. Drafting the manuscript: YS, HB, MDP, GG, CH, GL, SL, TM, JWM, LPM, MS, WS, BSC and JWvdL. Revising or reviewing the manuscript: YS, HB, MDP, GG, CH, SJ, GL, SL, TM, JWM, LPM, MS, WS, BSC, $\mathrm{KY}$ and JWvdL. All authors have approved the final manuscript.

\section{Acknowledgments}

The authors thank Ms. Mercedes Serabian (US Food and Drug Administration, CBER OTAT) for her leadership as co-chair of the HESI CT-TRACS Committee $(2016,2017)$ and her valuable expert input in the discussions leading to this article; Ms. Alexandra Feitel for programmatic support of the HESI CT-TRACS committee; and Ms. Christina West for manuscript review and editorial support.

\section{References}

[1] de Wilde S, Guchelaar HJ, Zandvliet ML, Meij P. Clinical development of gene- and cell-based therapies: overview of the European landscape. Mol Ther Methods Clin Dev 2016;3:16073.
[2] Bersenev A. Cell therapy clinical trials-2014 report. Cell Trials 2015. http://celltrials.info/2015/01/22/2014-report/ [accessed 7 February 2019].

[3] Priest CA, Manley NC, Denham J, Wirth ED 3rd, Lebkowski JS. Preclinical safety of human embryonic stem cellderived oligodendrocyte progenitors supporting clinical trials in spinal cord injury. Regen Med 2015;10:939-58.

[4] Kanemura H, Go MJ, Shikamura M, Nishishita N, Sakai N, Kamao H, et al. Tumorigenicity studies of induced pluripotent stem cell (iPSC)-derived retinal pigment epithelium (RPE) for the treatment of age-related macular degeneration. PLoS One 2014;9:e85336.

[5] Abbot S, Agbanyo F, Ahlfors JE, Baghbaderani BA, Bartido $\mathrm{S}$, Bharti $\mathrm{K}$, et al. Report of the international conference on manufacturing and testing of pluripotent stem cells. Biologicals 2018;56:67-83.

[6] Sato Y. Japan's new steps for ensuring quality, safety and efficacy of cell therapy products. In: Presented at the World Stem Cell Summit 2018, Miami, FL, USA; 24 January 2018. https://www.youtube.com/watch? $=$ KDbr5bXrAXg.

[7] Health and Environmental Sciences Institute. Presentation SY-04-5 ("Driving Translation of Cell-Based Therapies: An International Consortia to Develop Tools for Safety Assessment"). In: at the 16th Annual Congress of the Japanese Society for Regenerative Medicine; 7 March 2017, Sendai, Japan; 2017. http://www.congre.co.jp/jsrm16/program.html [accessed 30 April 2019].

[8] Health and Environmental Sciences Institute. CT-TRACS Scientific Session ("Identifying and Optimizing Emerging Technologies to Evaluate Cell Therapy Safety, MOA and Efficacy"). In: at the International Society of Cellular Therapy 2017 Annual Meeting; 6 May 2017, London, UK; 2017. https://cdn.ymaws. com/www.celltherapysociety.org/resource/resmgr/2017_london/ ISCT2017Program.pdf [accessed 30 April 2019].

[9] Health and Environmental Sciences Institute. HESI CTTRACS Lunch Seminar ("Global Regulatory Perspectives" preconference workshop: "Safety Assessment of Cell Therapy Products: Challenges and Current Advances. In: Perspectives From a New International Multi-Stakeholder Collaborative Platform") at the International Society of Cellular Therapy Annual Meeting 2018; 2 May 2018, Montreal, Québec, Canada; 2018. https://cdn.ymaws.com/www.celltherapysociety. org/resource/resmgr/2018_annualmtgpresentations/book-isct2018program_final.pdf [accessed 30 April 2019].

[10] Health and Environmental Sciences Institute. CT-TRACS and Cell and Gene Therapy Joint Workshop ("Safety Assessment of Cell Therapy Products: Current Advances and Challenges"). In: at the UK Cell and Gene Therapy Catapult 1st Seminar Series; 14 February 2018, London, UK; 2018. https://hesiglobal.org/event/cell-and-gene-therapy-catapult-seminar-series-cttracs-workshop/ [accessed 30 April 2019].

[11] Hentze H, Soong PL, Wang ST, Phillips BW, Putti TC, Dunn NR. Teratoma formation by human embryonic stem cells: evaluation of essential parameters for future safety studies. Stem Cell Res 2009;2:198-210.

[12] Yasuda S, Kusakawa S, Kuroda T, Miura T, Tano K, Takada N, et al. Tumorigenicity-associated characteristics of human iPS cell lines. PLoS One 2018;13:e0205022.

[13] Andrews PW, Ben-David U, Benvenisty N, Coffey P, Eggan $\mathrm{K}$, Knowles BB, et al. Assessing the safety of human pluripotent stem cells and their derivatives for clinical applications. Stem Cell Rep 2017;9:1-4.

[14] European Medicines Agency. EMEA/CHMP/410869/2006 Guideline on human cell-based medicinal products https:// www.ema.europa.eu/documents/scientific-guideline/guidelinehuman-cell-based-medicinal-products_en.pdf; 2008 [accessed 7 February 2019]. 
[15] International Conference on Harmonization. Q5D: Derivation and characterisation of cell substrates used for production of biotechnological/biological products. https:// www.ich.org/fileadmin/Public_Web_Site/ICH_Products/ Guidelines/Quality/Q5D/Step4/Q5D_Guideline.pdf; 1997 [accessed 7 February 2019].

[16] European Pharmacopoeia. Ph. Eur. General Text 5.2.3: Cell substrates for the production of vaccines for human use (01/ 2008:50203). https://www.edqm.eu/en/european-pharmacopoeia-ph-eur-9th-edition; 2008 [accessed 7 February 2019].

[17] European Medicines Agency. EMA/CAT/571134/2009 Reflection paper on stem cell-based medicinal products. https://www.ema.europa.eu/documents/scientific-guideline/ reflection-paper-stem-cell-based-medicinal-products_en.pdf; 2011 [accessed 7 February 2019].

[18] Barkholt L, Flory E, Jekerle V, Lucas-Samuel S, Ahnert P, Bisset L, et al. Risk of tumorigenicity in mesenchymal stromal cell-based therapies-Bridging scientific observations and regulatory viewpoints. Cytotherapy 2013;15:753-9.

[19] US Food and Drug Administration. In: CTGTAC Meeting \#45: Cellular therapies derived from human embryonic stem cells-Considerations for pre-clinical safety testing and patient monitoring (April 10, 2008); 2008. http://files. shareholder.com/downloads/ABEA-34B0DW/0x0x4116 46/92d81d5a-6b2d-44aa-8f5c-c1184d1ed4d5/FDA.pdf [accessed 24 September 2018].

[20] US Food and Drug Administration. Guidance for Industry: Preclinical assessment of investigational cellular and gene therapy products. https://www.fda.gov/downloads/BiologicsBloodVaccines/GuidanceComplianceRegulatoryInformation/Guidances/CellularandGeneTherapy/UCM376521.pdf; 2013 [accessed 7 February 2019]

[21] Hayakawa T, Aoi T, Umezawa A, Ozawa K, Sato Y, Sawa Y, et al. A study on ensuring the quality and safety of pharmaceuticals and medical devices derived from the processing of autologous human somatic stem cells (Notification No. 0907-2). Regen Ther 2015;2:57-69.

[22] Hayakawa T, Aoi T, Umezawa A, Ozawa K, Sato Y, Sawa Y, et al. A study on ensuring the quality and safety of pharmaceuticals and medical devices derived from the processing of allogeneic human somatic stem cells (Notification No. 09073). Regen Ther 2015;2:70-80.

[23] Hayakawa T, Aoi T, Umezawa A, Ozawa K, Sato Y, Sawa Y, et al. A study on ensuring the quality and safety of pharmaceuticals and medical devices derived from processing of autologous human induced pluripotent stem(-like) cells (Notification No. 0907-4). Regen Ther 2015;2:81-94.

[24] Hayakawa T, Aoi T, Umezawa A, Ozawa K, Sato Y, Sawa Y, et al. A study on ensuring the quality and safety of pharmaceuticals and medical devices derived from processing of allogeneic human induced pluripotent stem(-like) cells (Notification No. 0907-5). Regen Ther 2015;2:95-108.

[25] Hayakawa T, Aoi T, Umezawa A, Ozawa K, Sato Y, Sawa Y, et al. A study on ensuring the quality and safety of pharmaceuticals and medical devices derived from the processing of human embryonic stem cells (Notification No. 0907-6). Regen Ther 2015;2:109-22.

[26] World Health Organization. World Health Organization Technical Report Series No. 987 Annex 3. 2013. In: Recommendations for the evaluation of animal cell cultures as substrates for the manufacture of biological medicinal products and for the characterization of cell bank; 2013. http://www.who.int/biologicals/vaccines/TRS_978_Annex_3.pdf [accessed 24 September 2018].

[27] In: International Conference on Harmonization. Guideline S1: Rodent carcinogenicity studies for human pharmaceuticals; 2012. https://www.ich.org/fileadmin/Public_Web_Site/
ICH Products/Guidelines/Safety/S1/S1_Concept Paper_14_November_2012.pdf [accessed 7 February 2019].

[28] Lee AS, Tang C, Rao MS, Weissman IL, Wu JC. Tumorigenicity as a clinical hurdle for pluripotent stem cell therapies. Nat Med 2013;19:998-1004. https://doi.org/10.1038/ nm.3267.

[29] Sullivan S, Stacey GN, Akazawa C, Aoyama N, Baptista R, Bedford P, et al. Quality control guidelines for clinical-grade human induced pluripotent stem cell lines. Regen Med 2018;13:859-66.

[30] International Conference on Harmonization. Q2(R1): Validation of Analytical Procedures: Text and Methodology. https://www.ich.org/fileadmin/Public_Web_Site/ICH_Products/Guidelines/Quality/Q2_R1/Step4/Q2_R1_Guideline. pdf [accessed 25 June 2019].

[31] Ito E, Miyagawa S, Takeda M, Kawamura A, Harada A, Iseoka $\mathrm{H}$, et al. Tumorigenicity assay essential for facilitating safety studies of hiPSC-derived cardiomyocytes for clinical application. Sci Rep 2019;9:1881.

[32] Ito M, Hiramatsu H, Kobayashi K, Suzue K, Kawahata M, Hioki K, et al. NOD/SCID/gamma(c)(null) mouse: an excellent recipient mouse model for engraftment of human cells. Blood 2002;100:3175-82.

[33] Ishikawa F, Yasukawa M, Lyons B, Yoshida S, Miyamoto T, Yoshimoto G, et al. Development of functional human blood and immune systems in NOD/SCID/IL2 receptor \{gamma\} chain(null) mice. Blood 2005;106:1565-73.

[34] Machida K, Suemizu H, Kawai K, Ishikawa T, Sawada R, Ohnishi Y, et al. Higher susceptibility of NOG mice to xenotransplanted tumors. J Toxicol Sci 2009;34:123-7.

[35] Quintana E, Shackleton M, Sabel MS, Fullen DR, Johnson TM, Morrison SJ. Efficient tumour formation by single human melanoma cells. Nature 2008;456:593-8.

[36] Kusakawa S, Machida K, Yasuda S, Takada N, Kuroda T, Sawada $\mathrm{R}$, et al. Characterization of in vivo tumorigenicity tests using severe immunodeficient NOD/Shi-scid IL2R $\gamma$ null mice for detection of tumorigenic cellular impurities in human cell-processed therapeutic products. Regen Ther 2015;1:30-7.

[37] Gowing G, Shelley B, Staggenborg K, Hurley A, Avalos P, Victoroff J, et al. Glial cell line-derived neurotrophic factorsecreting human neural progenitors show long-term survival, maturation into astrocytes, and no tumor formation following transplantation into the spinal cord of immunocompromised rats. Neuroreport 2014;25:367-72.

[38] Lin B, McLelland BT, Mathur A, Aramant RB, Seiler MJ. Sheets of human retinal progenitor transplants improve vision in rats with severe retinal degeneration. Exp Eye Res 2018;174:13-28.

[39] Sareen D, Gowing G, Sahabian A, Staggenborg K, Paradis R, Avalos P, et al. Human induced pluripotent stem cells are a novel source of neural progenitor cells (iNPCs) that migrate and integrate in the rodent spinal cord. J Comp Neurol 2014;522:2707-28.

[40] Lu P, Woodruff G, Wang Y, Graham L, Hunt M, Wu D, et al. Long-distance axonal growth from human induced pluripotent stem cells after spinal cord injury. Neuron 2014;83:789-96.

[41] Shih CC, Forman SJ, Chu P, Slovak M. Human embryonic stem cells are prone to generate primitive, undifferentiated tumors in engrafted human fetal tissues in severe combined immunodeficient mice. Stem Cells Dev 2007;16:893-902.

[42] Suzuki M, Mose ES, Montel V, Tarin D. Dormant cancer cells retrieved from metastasis-free organs regain tumorigenic and metastatic potency. Am J Pathol 2006;169:673-81.

[43] Schneider G, Schmidt-Supprian M, Rad R, Saur D. Tissuespecific tumorigenesis: context matters. Nat Rev Cancer 2017;17:239-53. 
[44] Wang M, Zhao J, Zhang L, Wei F, Lian Y, Wu Y, et al. Role of tumor microenvironment in tumorigenesis. J Cancer 2017;8:761-73.

[45] Kuroda T, Yasuda S, Kusakawa S, Hirata N, Kanda Y, Suzuki K, et al. Highly sensitive in vitro methods for detection of residual undifferentiated cells in retinal pigment epithelial cells derived from human iPS cells. PLoS One 2012;7:e37342.

[46] Kuroda T, Yasuda S, Matsuyama S, Tano K, Kusakawa S, Sawa Y, et al. Highly sensitive droplet digital PCR method for detection of residual undifferentiated cells in cardiomyocytes derived from human pluripotent stem cells. Regen Ther 2015;2:17-23.

[47] Kono K, Takada N, Yasuda S, Sawada R, Niimi S, Matsuyama A, et al. Characterization of the cell growth analysis for detection of immortal cellular impurities in human mesenchymal stem cells. Biologicals 2015;43:146-9.

[48] Hasebe-Takada N, Kono K, Yasuda S, Sawada R, Matsuyama A, Sato Y. Application of cell growth analysis to the quality assessment of human cell-processed therapeutic products as a testing method for immortalized cellular impurities. Regen Ther 2016;5:49-54.

[49] Kusakawa S, Yasuda S, Kuroda T, Kawamata S, Sato Y. Ultra-sensitive detection of tumorigenic cellular impurities in human cell-processed therapeutic products by digital analysis of soft agar colony formation. Sci Rep 2015;5:17892.

[50] Chen J, Shi ZP, Dong J, Liao TT, Wang YP, Sun XP, et al. Evaluation of $\mathrm{x}$-inactivation status and cytogenetic stability of human dermal fibroblasts after long-term culture. Int J Cell Biol 2010;2010:289653.

[51] Allahbakhshian-Farsani M, Abdian N, Ghasemi-Dehkordi P, Sadeghiani M, Saffari-Chaleshtori J, Hashemzadeh-Chaleshtori M, et al. Cytogentic analysis of human dermal fibroblasts (HDFs) in early and late passages using both karyotyping and comet assay techniques. Cytotechnology 2014;66:815-22.

[52] Popp B, Krumbiegel M, Grosch J, Sommer A, Uebe S, Kohl $Z$, et al. Need for high-resolution genetic analysis in iPSC: results and lessons from the ForIPS Consortium. Sci Rep 2018;8:17201.

[53] Amps K, Andrews PW, Anyfantis G, Armstrong L, Avery S, Baharvand $\mathrm{H}$, et al. Screening ethnically diverse human embryonic stem cells identifies a chromosome 20 minimal amplicon conferring growth advantage. Nat Biotechnol 2011;29:1132-44.

[54] Peterson SE, Garitaonandia I, Loring JF. The tumorigenic potential of pluripotent stem cells: What can we do to minimize it? Bioessays 2016;38(Suppl 1):S86-95.

[55] Martincorena I, Roshan A, Gerstung M, Ellis P, Van Loo P, McLaren S, et al. Tumor evolution. High burden and pervasive positive selection of somatic mutations in normal human skin. Science 2015;348:880-6.

[56] Yizhak K, Aguet F, Kim J, Hess JM, Kübler K, Grimsby J, et al. RNA sequence analysis reveals macroscopic somatic clonal expansion across normal tissues. Science. 2019;364(6444).

[57] Bell JM, Lau BT, Greer SU, Wood-Bouwens C, Xia LC, Connolly ID, et al. Chromosome-scale mega-haplotypes enable digital karyotyping of cancer aneuploidy. Nucleic Acids Res 2017;45:e162.

[58] Zhu H, Huang SM, Madabushi R, Strauss DG, Wang Y, Zineh I. Model-Informed Drug Development: A Regulatory Perspective on Progress. Clin Pharmacol Ther 2019;106:91-3.

[59] Caballero D, Kaushik S, Correlo VM, Oliveira JM, Reis RL, Kundu SC. Organ-on-chip models of cancer metastasis for future personalized medicine: from chip to the patient. Biomaterials 2017;149:98-115.
[60] Manley NC, Priest CA, Denham J, Wirth ED 3rd, Lebkowski JS. Human embryonic stem cell-derived oligodendrocyte progenitor cells: preclinical efficacy and safety in cervical spinal cord injury. Stem Cells Transl Med 2017;6:1917-29.

[61] Itakura G, Kobayashi Y, Nishimura S, Iwai H, Takano M, Iwanami A, et al. Controlling immune rejection is a fail-safe system against potential tumorigenicity after human iPSC-derived neural stem cell transplantation. PLoS One 2015;10:e0116413.

[62] Itakura G, Kawabata S, Ando M, Nishiyama Y, Sugai K, Ozaki M, et al. Fail-safe system against potential tumorigenicity after transplantation of iPSC derivatives. Stem Cell Rep 2017;8:673-84.

[63] Lee DW, Kochenderfer JN, Stetler-Stevenson M, Cui YK, Delbrook C, Feldman SA, et al. T cells expressing CD19 chimeric antigen receptors for acute lymphoblastic leukaemia in children and young adults: a phase 1 dose-escalation trial. Lancet 2015;385:517-28.

[64] Neelapu SS, Locke FL, Bartlett NL, Lekakis LJ, Miklos DB, Jacobson CA, et al. Axicabtagene ciloleucel CAR T-cell therapy in refractory large B-cell lymphoma. N Engl J Med 2017;377:2531-44.

[65] Park JH, Riviere I, Gonen M, Wang X, Senechal B, Curran KJ, et al. Long-term follow-up of CD19 CAR therapy in acute lymphoblastic leukemia. N Engl J Med 2018;378:449-59.

[66] European Medicines Agency. EMEA/149995/2008 rev. 1 Guideline on safety and efficacy follow-up and risk management of advanced therapy medicinal products. https://www.ema. europa.eu/documents/scientific-guideline/draft-guideline-safetyefficacy-follow-risk-management-advanced-therapy-medicinalproducts-revision_en.pdf; 2017 [accessed 7 February 2019].

[67] Okada K, Sato Y, Sugiyama D, Sawa Y. Establishment of the National Consortium for Regenerative Medicine and National Regenerative Medicine Database in Japan. Clin Ther 2018;40:1076-83.

[68] European Medicines Agency. Yescarta: EPAR - Risk-management-plan summary. https://www.ema.europa.eu/en/documents/rmp-summary/yescarta-epar-risk-management-plansummary_en.pdf [last updated 10 September 2018, accessed 25 June 2019].

[69] European Medicines Agency. Kymriah: EPAR—Risk-management-plan summaryhttps://www.ema.europa.eu/en/documents/rmp-summary/kymriah-epar-risk-management-plansummary_en.pdf [last updated 19 September 2018, accessed 25 June 2019]

[70] Pasquini M.C.Cellular Therapy for Regenerative Medicine (\&More): Update of Cellular Therapy Registry. https://www. cibmtr.org/Meetings/Materials/CRPDMC/Documents/201 2/Feb\%202012/PasquiniM_CellularTherapy.pdf[accessed 25 June 2019]

[71] NIH, FDA. Agenda: NIH and FDA. In: "Regenerative Medicine and Innovation Workshop"; 6 December 2017, Bethesda, MD; 2017. https://www.nih.gov/sites/default/files/ research-training/initiatives/rmi/rmi-workshop-20171206-agenda.pdf [accessed 30 April 2019].

[72] NIH, FDA. Video Recordings: NIH and FDA. In: "Regenerative Medicine and Innovation Workshop"; 6 December 2017, Bethesda, MD; 2017. https://www.nih.gov/ research-training/medical-research-initiatives/rmi.

[73] International Alliance for Biological Standardization. In: 4th Cell Therapy Conference: Manufacturing and Testing of Pluripotent Stem Cells; 2018. http://4th-cell-therapy-conference.iabs.org [accessed 7 February 2019].

[74] Berkowitz AL, Miller MB, Mir SA, Cagney D, Chavakula V, Guleria I, et al. Glioproliferative lesion of the spinal cord as a complication of "stem-cell tourism. $\mathrm{N}$ Engl J Med 2016;375:196-8. 
[75] Thirabanjasak D, Tantiwongse K, Thorner PS. Angiomyeloproliferative lesions following autologous stem cell therapy. J Am Soc Nephrol 2010;21:1218-22.

[76] European Medicines Agency. Guideline on the nonclinical studies required before first clinical use of gene therapy medicinal products (EMEA/CHMP/GTWP/125459/2006). https://www.ema.europa.eu/documents/scientific-guideline/ guideline-non-clinical-studies-required-first-clinical-use-ge ne-therapy-medicinal-products_en.pdf; 2008 [accessed 7 Fe bruary 2019].

[77] European Medicines Agency. EMA/CAT/GTWP/671639/2008 Guideline on quality, non-clinical and clinical aspects of medicinal products containing genetically modified cells. https://www. ema.europa.eu/documents/scientific-guideline/guideline-quality-non-clinical-clinical-aspects-medicinal-products-containinggenetically-modified_en.pdf; 2012[accessed 7 February 2019].

[78] Tano K, Yasuda S, Kuroda T, Saito H, Umezawa A, Sato $\mathrm{Y}$. A novel in vitro method for detecting undifferentiated human pluripotent stem cells as impurities in cell therapy products using a highly efficient culture system. PLoS One 2014;9:e110496.

[79] Tateno H, Onuma Y, Ito Y, Hiemori K, Aiki Y, Shimizu M, et al. A medium hyperglycosylated podocalyxin enables noninvasive and quantitative detection of tumorigenic human pluripotent stem cells. Sci Rep 2014;4:4069.

[80] Zhang Y, Feng GH, Xu K, Wang L, Cui P, Li Y, et al. A non-invasive method to determine the pluripotent status of stem cells by culture medium microRNA expression detection. Sci Rep 2016;6:22380.

[81] Kono K, Takada N, Yasuda S, Sawada R, Niimi S, Matsuyama A, et al. Corrigendum to "Characterization of the cell growth analysis for detection of immortal cellular impurities in human mesenchymal stem cells" [Biologicals 43 (2) (March 2015) 146149]. Biologicals 2017;45:106.

[82] Stephenson E, Ogilvie CM, Patel H, Cornwell G, Jacquet L, Kadeva N, et al. Safety paradigm: genetic evaluation of therapeutic grade human embryonic stem cells. J R Soc Interface 2010;7(Suppl 6):S677-88. 